\title{
Livestock Tackles the Major Sector Fluctuations in Agrarian Sector and Raises Economic Performance: A Study of Pakistan
}

\author{
Muhammad Shahid ${ }^{1}$, Adiqa Kiani ${ }^{2 *}$ and Mahmood Shah ${ }^{3}$
}

${ }^{1}$ Head of Department of Economics, Govt. Post Graduate College, Bhakkar, Punjab, Pakistan; ${ }^{2}$ Federal Urdu University, Islamabad, Pakistan; ${ }^{3}$ Gomal University, Dera Ismail Khan, Pakistan.

Abstract | This research paper focuses the ambiguous analysis of livestock sector in raising the level of economic
performance. The study reveals implications of livestock in tackling seasonal fluctuations, inputs shocks and
failure of crops in major sector by taking time series data from 1984 to 2017 . Auto regressive distributive
lag (ARDL) econometric technique was applied to conclude empirical results. Further, cumulative sum
(CUSUM) and CUSUM square test was used to check the stability and structural breaks of the model. The
results of research show the statistical significant and positive impact of livestock on economic performance
while inflation effect on economic performance is insignificant. I have reviewed a lot of economic literature
but not found single one study of this nature. This comprehensive research will assist the govt. in making
policies on livestock to revive the economic performance of the country.
Received | October 23, 2019; Accepted | June 06,$2020 ;$ Published | July 29,2020
*Correspondence $\mid$ Adiqa Kiani, Associate Professor Federal Urdu University, Islamabad, Pakistan; Email: drkianiupenn@gmail.com
Citation | Shahid, M., A. Kiani and M. Shan. 2020 . Livestock tackles the major sector fluctuations in agaric sector and raises economic
performance: A study of Pakistan. Sarbad Journal of Agriculture, 36(3): $761-767$.
DOI $\mid$ http://dx.doi.org/10.17582/journal.sja/2020/36.3.761.767
Keywords $\mid$ Livestock, Productivity of labour, Inflation, Exchange rate

\section{Introduction}

$\mathrm{T}$ he most productive and prominent sector livestock has shared more than $70 \%$ production for rural areas. This animal sector contributes to GDP of rural agricultural sector is $55.4 \%$ and endows 11.9 $\%$ in GDP of Pakistan. Farm sector in the agriculture economy has the potential to tackle seasonal, cyclical fluctuations, shocks and covers the deficiency of inputs of agricultural and crops sector when the major sector fails due to some mishappenings. This sector helps also in producing meat, eggs, food, generating employments opportunities, soil preparing and many beyond of these other. Some researchers consider the livestock as natural capital source of food, soil production, supporting of agaric sector.
Livestock sector also makes significant contribution towards preservation of environment. The Livestock sector raises the income of agrarian production and other sources and absorbs outputs shocks due to crop failure. It generates a continuous stream of income and employment and reduces seasonal effects in the livelihood patterns particularly of the rural poor people (Economic Survey of Pakistan, 2012-13), (Birthal and Ali, 2005).

In the recent and modern literature, the physical capital to improve economic performance and development has been divided in five sub categories as:

1. Natural capital consists of water, wild plants and natural resources of land, animals, birds and fish.

2. Social capital facilitates the social transaction. 
3. Physical capital comprises of human productivity activity of the past.

4. Human capital is the man-made skills and techniques.

5. Financial capital is money and funding resources.

The poultry sector in Pakistan is sub divided into domestic and commercial sectors which contribute the total meat production of 1.39 million tons in $2017-18$. It is $32.7 \%$ share of the total meat of the country. These two sub sectors as the livestock sector which contributes the agaric sector $7.5 \%$ and poultry sector share the GDP of the agriculture sector up to $12.5 \%$. During the 12017-18 Pakistan has exported poultry meat of US $\$ 105.541$ million. So, this sector has potential to raise the economic performance of the country.

In the history, the human being and animals has been associated with each other in agricultural and rural society. The livestock is used to plough, riding, food and other economic purposes and rural society or agriculture sector is uncompleted in the absence of animals. In most traditional society, the cattle are the sign of prestige and discrimination in the agricultural society. These animals have economic consequences and implications on development of the production of agaric sector. The production sector is linked with risks from natural and climatic changes, emerges in the form of floods, erosion of land, diseases and economic fluctuation in price reduces the output of the agriculture sector. In such economic risky situation of agriculture sector, the livestock sector mitigates the risky factors in to account and tackles the economic loss of major agricultural sector (Savvides, 1994).

In Pakistan, the role of livestock in agriculture and rural development has been underestimated. Although it produces diversified items of food like mutton, beef, chicken, fish, eggs, and yogurt, milk, butter, wool and lather products. It contributes the numbers of economic goods and services with additional hard cash resources to the farming sector. The animal sector mitigates the risks of farming sector and raises income, employment and production of agrarian sector. The farmers can get sustainable farming techniques and machinery by selling livestock population and products. Despite the numerous benefits of livestock production, many institutions and policy makers have imposed restrictions on the livestock production that have to be discussed in this study which will expose the complications of animal system of production and provide great opportunity of development of agaric sector $(\mathrm{FAO}, 1994)$.

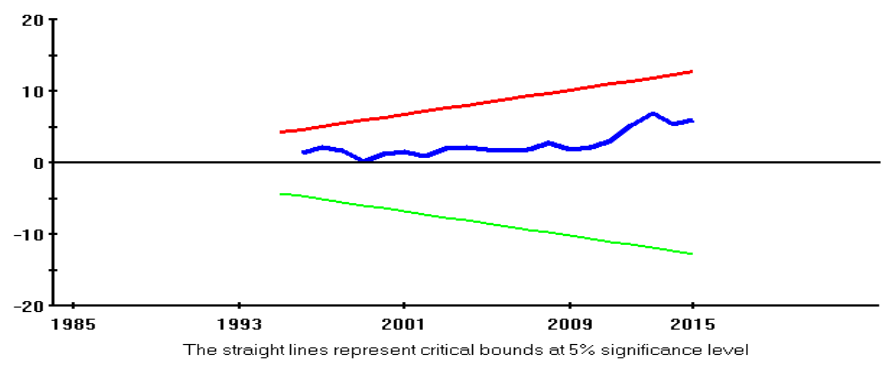

Figure 1: Plot of cumulative sum of recursive residuals. Red lines shows the upper control limit, green shows lower control limit and blue shows average drawn from original data.

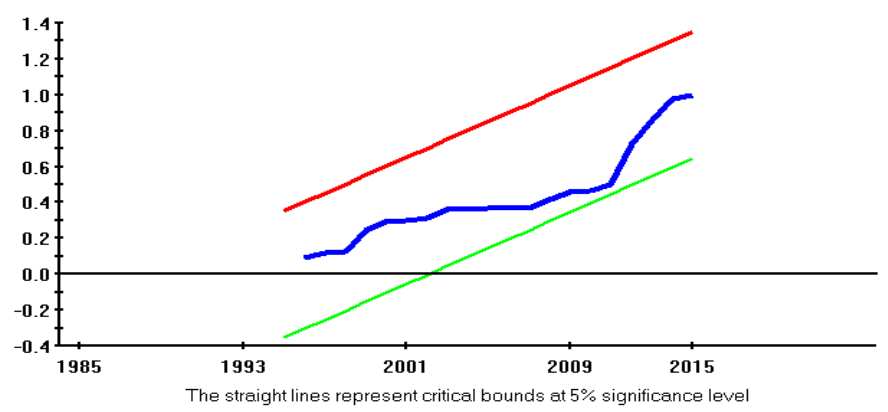

Figure 2: Cumulative sum of square of recursive residuals

Red lines shows the upper control limit, green shows lower control limit and blue shows average drawn from original data.

Despite the numerous benefits of livestock production, many institutions expose the complications of animal system of production and provide great opportunity of development of agaric sector. So, the link between livestock sector and agriculture sector becomes valuable for developmental goal. To get these advantages of animal sector an appropriate and empirical study on this topic is required. Against this background the study focuses on livestock production for raising level of economic performance of the country and rural areas in short run as well as long run and suggest government to pay more attention to this third force (Livestock the Sub Sector of Agaric Sector) to take out the economy away from economic hurdles and can improve the economic performance of Pakistan.

\section{Literature review}

Chandio et al. (2015) launched the research on different fields of economy as agriculture, livestock, forestry and minor crops and showed their impact on economic performance by taking dataset over the period 1998-2015. The OLS econometric technique was applied to conclude the empirical results. The study purposed advanced technology and 
improvement of subsector to get the target of better economic performance.

Anwer et al. (2015) examined the agricultural, industrial and trade sectors of the economy and showed their effect on GDP of Pakistan by using dataset over the period from 1975-2012. OLS econometric technique was operated to find the results of the study. The study revealed significant and positive effect of agriculture sector on GDP in case of Pakistan.

Zaheer (2013) investigated the theoretical research based on secondary dataset over the period from 19522010. The study revealed that growth has fluctuated in agaric sector during previous 60 years. But the research has suggested that agriculture is the most important to contribute the economic performance if the lack of technology and irrigations problems are removed.

Pandit et al. (2012) analyzed the role of livestock in rural areas to develop the food standard of the house hold by taking region of Punjab and used the data from 2009-10 of 12 district. Econometric binary regression technique was applied to found the empirical results. Livestock provide not only food but female species in livestock encourage economic performance through rise in GDP. Christin et al. (2011) debated the livestock sector to encourage the economic performance and to depresses the poverty. For results finding the research applies financial base approach and concludes that the impact of livestock sector on economic performance is positive while affects poverty negatively.

Pica et al. (2008) examined the data from 66 middle income and low-income countries and found Livestock sector has raised the economic growth and agricultural productivity of labor and proved engine of economic growth.

Pica et al. (2008) analyzed the cross-section data of 66 countries from 1961 to 2003 and found livestock development affects the economic performance positively. They concluded statistically significant impact of livestock on economic growth.

Income sources of Southern Nigerian farmers who earn more than $80 \%$ from poultry products like chicken and egg was investigated by Fasina et al. (2007). So, livestock sector enhances the cash resources which encourage the labor productivity of labors and farming people.

Rota and Sidahmed (2010) analyzed that livestock products have supplied a specific standard of food and nutrition. In rural areas the poor families can easily utilized livestock in improving the mental health of their children and provides them source of income which has improved the economic performance of the economy.

Ali (2007) investigated in India that about $70 \%$ rural families were without land but they had goats, sheep, cows, poultry and buffalo. These livestock animals have become the economic growth engine for economic performance. This sector has the potential to earn foreign exchange earnings to encourage the economic growth. However, Hollmann et al. (2005) selected 5 region in Colombia to interview of 143 of such farmers who have sold out their livestock products to pay off debt, purchase of inputs or to face the crop failure. They found solid reason of having livestock to improve the capital and saving. Further it improves the economic performance and quality of life.

Kristjanson et al. (2004) showed the livestock as the third sector to encourage economic performance in Kenya by taking 20 villages of districts. This sector has contributed $24 \%$ improvements of all families in economic performance. Further the study has also proposed the reason of poverty in rural areas is the lack of livestock. On the other hand, Bruinsma (2003) analyzed that livestock along with its products have become halved output of total agriculture sector in developed industrial countries and third part of developing economies. It contributes not only income to the rural farmers but also encourages the productivity labor of agriculture sector.

Thornton et al. (2002) conducted research on mixed agaric system to promote the rural incomes of the country. The same practice is exercised in the world and livestock sector is financial supporting in crop failure. It contribute major share of income in GDP.

\section{Materials and Methods}

\section{Model specification and data source $G R=\beta_{0}+\beta_{1} L S I+\beta_{2} A P L W+\beta_{3} I N F+\beta_{4} E R+\varepsilon_{i}$ $G R=$ Real Gross Domestic Production is used as proxy to measure the Economic Performance.}


$L S I=$ Livestock index is used to measure the livestock of the country.

APLW = Average Productivity of labor per Worker in agricultural Rural Area.

INF = Inflation Rate,

$E R=$ exchange Rate

Time series data has been taken from World Development Indicator, Economic Survey of Pakistan and State Bank of Pakistan from the period 1984 to 2017 and ARDL econometric method was used.

\section{Unit root test}

Unit root test was applied to check the stationary and order of the data it was found that none of the variable is at second difference and some variables are at level I (0) and some are at first difference I (1). So, the most appropriate technique is Auto Regressive Distributive Lag which requires no variables should be at $2^{\text {nd }}$ difference.

\section{Co integration}

To show the short-run and long-run relationship among economic performance, livestock, labor productivity, inflation and exchange rate the present research uses the error-correction version of $A R D L$ model of equation (A) by following Pesaran and Pesaran (1997) and Pesaran and Shin (1999) as:

$$
\begin{gathered}
\Delta G R_{t}=\alpha_{0}+\sum_{i=1}^{N} \propto_{1} \Delta G R_{t-i} \sum_{i=0}^{N} \alpha_{2} \Delta L S I_{t-i}+\sum_{i=0}^{N} \alpha_{3} \Delta A P L W_{t-i}+\sum_{i=0}^{N} \alpha_{4} \Delta I N F_{t-i}+\sum_{i=0}^{N} \alpha_{5} \Delta E R_{t-i} \\
+\beta_{1} G R_{t-1}+\beta_{2} L S I_{t-1}+\beta_{3} A P L W_{t-1}+\beta_{4} I N F_{t-1}+\beta_{5} E R_{t-1+} \mu \ldots .(\mathrm{A})
\end{gathered}
$$

The first step in ARDL approach to co-integration is to analyze long-run relationship among the variables by carrying out familiar F-statistic on the differenced variables components of Unrestricted Error Correction Mechanism (UECM) model for the joint significance of the coefficients of lagged level of the variables.

$$
\Delta G R=\alpha_{0}+\sum_{i=1}^{N} \alpha_{1} \Delta G R_{t-i}+\sum_{i=0}^{N} \alpha_{2} \Delta L S I_{t-i}+\sum_{i=0}^{N} \alpha_{3} \Delta L A P L W_{t-i}+\sum_{i=0}^{N} \alpha_{4} \Delta I N F_{t-i}+\sum_{i=0}^{N} \alpha_{5} \Delta E R_{t-i}+\mu_{t} \ldots(\mathrm{B})
$$

To create error correction mechanism in this equation, first Lag of the level of each variable is added to the equation (B) and a variable Addition Test is conducted by calculating $\mathrm{F}$-test on the joint significance of all the added lagged level variables. Results and Discussion
The above value of bound test statistics is 7.667 crosses the lower and upper bound critical limit values, bears the co-integration among GR, LSI, APLW, INF and ER while the GR is estimated as dependent variable (Table 1). Pesaran and Pesaran (1997) constructed two sets of critical bound values for large sample up to 500 which have different standard distribution. Lower values are associated to the variables which are at level and upper critical vales of bound test are nexus to the variables at first difference I (1). The calculated value of statistics runs over the critical values, rejects the null hypothesis (no co integration among variables exist) and accepts the alternative hypothesis (co integration among variables exist). If the value of bound statistics lies in between critical value, not support the co integrations among variables in long run.

\section{Table 1: Bound test.}

$\begin{array}{lllll}\text { F-calcu- } & \text { 95\% confidence interval } & \text { 90\% confidence interval } \\ \text { lated } & \text { Lower limit } & \text { Upper limit } & \text { Lower limit } & \text { Upper limit } \\ 7.667 & 3.366 & 4.799 & 2.772 & 4.027\end{array}$

Source: Author own calculation.

The computed value of F-Statistics exceeds the lower and upper values at $90 \%$ and $95 \%$ confidence interval presents co integration exists among variables in the long run.

In the Table 2 one unit rise in livestock the economic performance increases by .092 and this coefficient is statistically significant and efficient at $5 \%$ as t-ratio is more than 2 and $\mathrm{P}$-value is less than 5\%. The average productivity of labor and exchange rate also affect the economic performance positively and significant at $1 \%$ and $5 \%$ while inflation affects the economic performance is insignificant.

Table 2: Dynamic ARDL model based on schwarz lag estimates criterion.

$\begin{array}{llll}\text { Variables } & \text { Coefficients } & \text { T-ratios } & \text { P-values } \\ \text { GR }(-1) & 0.258 & 1.758 & (.093) \\ \text { LSI } & 0.092 & 2.223 & (.037) \\ \text { APLW } & .019 & 2.184 & (.040) \\ \text { APLW(-1) } & -.032 & 4.205 & (.000) \\ \text { INF } & -.017 & .316 & (.316) \\ \text { ER } & 0.126 & 2.815 & (.010)\end{array}$

Source: Author own calculation.

The $\mathrm{R}^{2}$ value is 0.551 explains the $55.1 \%$ variation 
in model is attributed to the explanatory variables; the other $44.9 \%$ variation in model is the result of other factors (Table 3). The Durban statistics value is close to 2, no problem of autocorrelation. The value of F-statistics value is higher represents that all variables effect on the model reflects good fit of the model.

Table 3: Good fit model.

$\begin{array}{ll}\mathrm{R}^{2} & .651 \\ \text { Adjusted R }^{2} & .551 \\ \text { D.W-Statistics } & 1.877 \\ \mathrm{~F}(6,21) & 6.534\end{array}$

Source: Author own calculation.

The diagnostic test in Table 4 is discussed where p-value LM-version and F-Version is higher than $10 \%$ or 0.1 percent, expresses the error terms are not correlated with each other. The expression is also elaborated by Lagrange Multiplier test. Ramsey Reset test is attributed to the correct functional form of the model as same philosophy is illustrated by the $\mathrm{p}$-value of LM- Version and F-Version is above from $10 \%$. In time series model there is fewer chances of Heteroscedasticity.

Table 4: Diagnostic test.

$\begin{array}{lll}\text { Problem } & \text { LM-version (P.V) } & \text { F-version (P.V) } \\ \text { Serial Correlation } & (.686) & (.735) \\ \text { Functional Form } & (.152) & (.223) \\ \text { Normality } & (.890) & \text { Not applicable } \\ \text { Heteroscdasticity } & (.147) & (.158)\end{array}$

Source: Author own calculation.

\section{Stability test}

The stability test of Cumulative Sum of square of Recursive residual and CUSUM sum of square tests are constructed by Brown et al. (1975). The CUSUM and CUSUM SQUARE lines adopt within 5\% critical bound limit, represents the stability of the model in long run variables attached with SR dynamics. A between $5 \%$ bound limit line shows the relationship among variables is stable and model is not associated with structural breaks.

The long run results of the model (Table 5) are crucial important that one unit increase in livestock index brings change in economic performance by 0.12 units as the t-ratio is 2.89 and $\mathrm{p}$-value is less than $5 \%$ shows the livestock statistically significant and efficient. The other economic variables like average productivity of labor per worker and exchange rate are also affect the economic performance positively and statistical significant at $1 \%$ and $5 \%$ while inflation effect is insignificant.

Table 5: Long run estimation of the model.

$\begin{array}{llll}\text { Variables } & \text { Coefficients } & \text { T-Ratios } & \text { P-Values } \\ \text { LSI } & 0.124 & 2.89 & (.049) \\ \text { APLW } & .018 & 2.509 & (.020) \\ \text { INF } & -.024 & .315 & (.715) \\ \text { ER } & .171 & 3.376 & (.001)\end{array}$

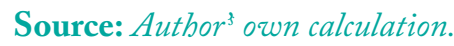

In short run one unit increases in livestock causes for raising in real GDP by 0.92 unit (Table 6) and livestock index is statistically significant reflected by $\mathrm{T}$-ratio is 2.223 more than 2 . The other variables average productivity of labor and exchange rate are also affect the GDP positivity and significant at 5\% and $1 \%$.

Table 6: Error correction model explanations.

$\begin{array}{llll}\text { Variables } & \text { Coefficients } & \text { t-Ratios } & \text { P-Values } \\ \text { Dlsi } & .092 & 2.223 & (.037) \\ \text { Daplw } & .019 & 2.184 & (.040) \\ \text { Dinf } & -.017 & 316 & (.755) \\ \text { DER } & .126 & 2.815 & (.010) \\ \text { Ecm }(-1) & -.741 & 5.04 & (.000)\end{array}$

Source: Authors own calculation.

The negative value of error coefficient represents the model highly significant and statistically significant at $1 \%$. The adjustment value is 0.74 means $74 \%$ adjustment capacity reserve in the model. This adjustment value $74 \%$ means disequilibrium in previous year will converge to equilibrium in the current year.

Empirical findings show that livestock is very important sector of Pakistan economy and it should not ignored . significance importance of livestock sector will not only increase the productivity and share in agriculture sector but also it increases the employment. Overall increase in the employment, productivity, percentage share in agriculture sector enhance GDP.

\section{Conclusions and Recommendations}


Historically it has been seen that the growth has emerged from livestock sector rather than crop sector. In most developing countries the livestock sector has increased rapidly than agaric sector. In Pakistan this sector has also contributed tremendous part of production to agaric sector. But unfortunately, the animal sector is restricted by poor support of government, low coordinated policies to the farming persons and minimal investment by public sector. Hence livestock sector is facing major challenges of technology, analytical instrument and non-availability of information.

The long run results are most crucial and important as 1 unit rises in livestock index causes increase in economic performance by 0.12 and statistically significant at $5 \%$ as shown by p-value which is .049 less than $5 \%$. The other variables productivity of labor and exchange rate affect the economic performance positively and statistically significant at $1 \%$ and $5 \%$ the effect of inflation on economic performance is insignificant. Short run results are as 1 unit change in livestock index economic performance will improve by 0.12 and statistically significant at $5 \%$. The other variables like productivity of labor and exchange rate affect the economic performance positively and significant at $1 \%$ and $5 \%$ while inflation brings negative change on economic performance and is statistically insignificant.

All diagnostic tests confirm the correct, no auto correlation and hetrorscdacity as P. Value of LM version and F-Version is more than $10 \%$. Cumulative Sum of Recursive Residual CUSUM and CUSUM sum of square tests showed the study without structural breaks as the graph lies in between 5\% critical bound values. Error correction coefficient ecm $(-1)$ is with negative sign shows the model is highly significant. The adjustment coefficient is 0.74 reflects $74 \%$ disequilibrium in previous year will converge to equilibrium in current period.

The study revealed that livestock sector has the potential to finance cash to the crop production. The appropriate framework, logical policies, development strategy for livestock sector should be formulated if we want to reap the economic and development advantage for agricultural sector and economic performance.

Novelty Statement
This research study investigated the role of livestock for enhancing economic growth in the agricultural sector of Pakistan.

\section{Author's Contribution}

Muhammad Shahid: Introduction, literature review and result interpretation.

Adiqa Kiani: Edited all manuscript, conclusion. Improved the quality of the paper.

Mahmood Shah: Guided throughout the reseach.

\section{Conflict of interest}

The authors have declared no conflict of interest.

\section{References}

Ali, J., 2007. Livestock sector development and implications for rural poverty alleviation in India. Livest. Res. Rural Dev., 19(27). Retrieved August 16, 2013, from http://www.lrrd.org/ lrrd19/2/ali19027.htm.

Annual Statistical Report, 2012-13. Poultry sector of Punjab, Pakistan.

Anwer, M.M., S. Farooqi and Y.D. Qureshi. 2015. Agriculture sector performance: An analysis through the role of agriculture sector share in GDP.J.Agric. Econ., Ext. Rural Dev.,3(3):270275. Retrieved from http://www.springjournals. net/full-articles/springjournals.netjaeerd.

Birthal, P.S. and J. Ali. 2005. Potential of livestock sector in rural transformation: In rural transformation in India: The Role of Nonfarm Sector. Inst. Hum. Dev. Manohar Publ. Distributors, New Delhi

Brown,R.L.,J.DurbinandJ.Evans.1975.Techniques for testing the constancy of regression relations over time. J. R. Stat. Soc., 37: 149-163. https:// doi.org/10.1111/j.2517-6161.1975.tb01532.x

Bruinsma, J. 2003. World agriculture towards 2015 / 2030, and FAO Perspective, London: Earth scan.

Chandio, A.A., Y. Jiang, R. Tanseerlur, M.N. Khan, G. Xu and Z. Zhao. 2015. Analysis of agricultural subsectors contribution growth rate in the agriculture GDP growth rate of Pakistan. Int. J. Hum. Soc. Sci. Invention, 4(8): 101-105.

Christin, C., V.Alary and G.Denis.2011.Livestock's contribution to poverty alleviation: How to measure it? World Dev., 39(9): 163-164.https:// 
doi.org/10.1016/j.worlddev.2011.02.008

Development in IFAD, IFAD's livestock position paper, International Fund for Agricultural Development (IFAD) Government of Pakistan, 2013-14. Economic Survey of Pakistan, Federal Bureau of Statistics, Statistics Division. Ministry of Economic Affairs and Statistics, Islamabad, Pakistan

Economic Survey of Pakistan (Various Issues), Federal Bureau of Statistics, Statistics Division. Ministry of Economic Affairs and Statistics, Islamabad, Pakistan

FAO, 1994. Methods of micro level analysis for agricultural programs and policies: A guideline for policy analysts. Rome, FAO.

FAO, 2003. FAO world livestock production system: Current status, issue and trend. FAO Anim. Prod. Health Pap. no.127 Rome, FAO

Fasina, F.O., M.D. Wai, S.N.Mohammed and O.N. Onyekonwu. 2007. Contribution of poultry production to household income: A case of Jos South Local Government in Nigeria. National Veterinary Research Institute Research Report No. 3. Family Poult. 17: 30-34.

Holmann, F., L. Rivas, N. Urbina, B. Rivera, L.A. Giraldo, S. Guzman, M. Martinez, A. Medina and G. Ramirez. 2005. The role of Livestock in Poverty Alleviation: An analysis of Colombia. Livest. Res. Rural Dev., 17

Kristjanson, P., M. Radeny and W. Nindo. 2004. Pathways out of poverty in western kenya and the role of livestock, PPLPI Working Paper No. 14 Pro Poor Livest. Policy Initiative (PPLPI), FAO, Rome.

Nayyar, R. and A.N. Sharma. 2005. Transformation in India: The Role of Non-farm Sector. Inst. Hum. Dev. Manohar Publ. Distributors, New
Delhi.

Pandit, R., M.K. Schilizzi and S. Bashir. 2012. Livestock and rural household food security: The case of small farmers of the punjab, pakistan. Sch. Agric. Resour. Econ., Univ. Western Aust., Crawley, Australia working paper 1207.

Pesaran, M.H. and B. Pesaran. 1997. Working with Microfit 4.0: Interact. Econ. Anal., Oxford Univ. Press.

Pesaran, M.H., Y. Shin and R.J. Smith. 1999. Bounds testing approaches to the analysis of level relationships. J. Appl. Econ., 16(3): 289326. https://doi.org/10.1002/jae.616

Pica, G., U.P. Ciamarra and J. Otte. 2008. The livestock sector in world development report 2008. Reassessing the Policy Priorities. FAOPPLPI Research Report 08-07. Rome, FAO.

Rota, A. and Sidahmed. 2010. Livestock Planning, Challenges and Strategies for Livestock Pesaran, M.H., and Pesaran, B. Working with Microfit 4.0: Interactive Econometric Analysis Oxford. Oxford University Press.

Savvides, S., 1994. Risk analysis in investment appraisal: Project appraisal, Surrey, UK, Beech Tree Publishing. 9(1): 3-18. https://doi.org/10 .1080/02688867.1994.9726923

Sprague, P., 2014. Bureau of Labor Statistics United States Department of Labor, May 2014 | Vol. 3 / No. 12.

Thornton, P.K., R.L. Kruska, N. Henninger, P.M. Kristjanson, R.S. Reid, F. Atieno, A. Nodero and T. Ndegwa. 2002. Mapping poverty and livestock in the developing world Nairobi. Int. Livest. Res. Inst.

Zaheer, R., 2013. Analyzing the performance of agriculture sector in Pakistan. Int. J. Hum. Soc. Sci. Invention, 2(5): 1-10. 